\title{
Fatal septic shock caused by Paracoccidioides brasiliensis phylogenetic species S1 in a young immunocompetent patient: a case report
}

\author{
Priscila Marques de Macedo ${ }^{[1]}$, Rodrigo Almeida-Paes ${ }^{[2]}$, Marcos de Abreu Almeida ${ }^{[2]}$, \\ Rowena Alves Coelho ${ }^{[2]}$, Marcio Amaral de Oliveira Filho ${ }^{[3]}$, Denise Machado Medeiros ${ }^{[3]}$, \\ Adriano Gomes-Silva ${ }^{[4]}$, Jéssica Ribeiro de Lima ${ }^{[5]}$, Alda Maria Da-Cruz ${ }^{[5]}$, \\ Rosely Maria Zancopé-Oliveira ${ }^{[2]}$, and Antonio Carlos Francesconi do Valle ${ }^{[1]}$
}

[1]. Laboratório de Pesquisa Clínica em Dermatologia Infecciosa, Instituto Nacional de Infectologia Evandro Chagas, Fiocruz, Rio de Janeiro, RJ, Brasil.

[2]. Laboratório de Micologia, Instituto Nacional de Infectologia Evandro Chagas, Fiocruz, Rio de Janeiro, RJ, Brasil.

[3]. Departamento de Medicina Intensiva, Instituto Nacional de Infectologia Evandro Chagas, Fiocruz, Rio de Janeiro, RJ, Brasil.

[4]. Laboratório de Pesquisa Clínica em Micobacterioses, Instituto Nacional de Infectologia Evandro Chagas, Fiocruz, Rio de Janeiro, RJ, Brasil.

[5]. Laboratório Interdisciplinar de Pesquisas Médicas, Instituto Oswaldo Cruz, Fiocruz, Rio de Janeiro, RJ, Brasil.

\begin{abstract}
The authors report the first case of fatal septic shock, a rare clinical presentation of paracoccidioidomycosis (PCM) caused by Paracoccidioides brasiliensis S1. We also provide an immunological evaluation of the patient. Severe clinical signs such as organ dysfunction and digital gangrene occurred in this case. The patient presented a remarkable cell activation profile and diminished percentage of peripheral blood T regulatory cells. A decrease in anti-inflammatory IL-1RA plasma level showed the potential for endothelium damage, probably contributing to a vasculitis process. Together with $P$. lutzii, P. brasiliensis appears to be involved in severe cases of PCM.
\end{abstract}

Keywords: Paracoccidioides brasiliensis S1. Septic shock. Host-parasite interaction.

\section{INTRODUCTION}

Paracoccidioidomycosis (PCM) is a severe systemic mycosis with a broad spectrum of clinical and immunological manifestations. These range from chronic PCM (adult type), accounting for $80-90 \%$ of cases that are mostly among male farm workers and usually affecting the lungs and oral mucosa, to acute/subacute PCM (juvenile type) in young susceptible patients presenting a more severe clinical condition because of intense reticuloendothelial system involvement ${ }^{1}$. Although it has been hypothesized that Paracoccidioides lutzii is associated with severe clinical forms, $P$. brasiliensis has also been recently reported to cause serious and unusual clinical pictures ${ }^{2,3}$.

\section{CASE REPORT}

A 19-year-old man from the Rio de Janeiro metropolitan area was admitted to Evandro Chagas National Institute of Infectious Diseases. His family reported a 6-month history of

Corresponding author: Dra. Priscila Marques de Macedo. e-mail: priscila.marques@ini.fiocruz.br

Received 3 August 2017

Accepted 1 December 2017 adenomegaly initially misdiagnosed as mumps. The patient's clinical condition had worsened during this time, with progressive lymph node enlargement, 10-kg weight loss, high fever, abdominal pain, and vomiting during the 2 months before admission. There was no report of travel, rural activities, or comorbidities, except marijuana smoking and bathing in the waterfalls of Gericinó Natural Park (Brazilian Atlantic Forest, Rio de Janeiro). Five days before hospital admission, the patient had increased vomiting frequency, abdominal distention, jaundice, and decreased consciousness level. At admission, the patient presented anasarca, bulky cervical lymph nodes, oliguria, and acute respiratory failure (oxygen saturation $60 \%$ by pulse oximetry) requiring tracheal intubation (Figure 1). Other important clinical signs were tachycardia (132bpm); bedside echocardiography showing inferior vena cava collapse, and fluid-refractory hypotension (mean arterial pressure - MAP 70 $\mathrm{mmHg}$ after $3 \mathrm{~L}$ of volume expansion and epinephrine infusion rate $14 \mathrm{~mL}$ per hour). Laboratory results after support treatment showed hemoglobin $6.6 \mathrm{~g} / \mathrm{dL}$ (reference value [RV]: $13-18 \mathrm{~g} / \mathrm{dL}$ ); leukocytosis $23,760 / \mathrm{mm}^{3}$ (RV: $4,200-10,000 / \mathrm{mm}^{3}$ ) with $33 \%$ band cells (RV: up to 7\%); elevated amounts of nitrogenous compounds in the blood (urea $459 \mathrm{mg} / \mathrm{dL}$ [RV: $15-38 \mathrm{mg} / \mathrm{dL}$ ], creatinine $2.74 \mathrm{mg} / \mathrm{dL}$ [RV: $0.7-1.3 \mathrm{mg} / \mathrm{dL}]$ ); serum lactate 6.3 $\mathrm{mmol} / \mathrm{L}$ (RV: $0.5-2.0 \mathrm{mmol} / \mathrm{L}$ ); hypoalbuminemia $0.9 \mathrm{~g} / \mathrm{dL}$ 
(RV: $3.4-5.0 \mathrm{~g} / \mathrm{dL}$ ); C-reactive protein $98.7 \mathrm{mg} / \mathrm{dL}$ (RV: $0.3 \mathrm{mg} / \mathrm{dL}$ ), and remarkable hypercalcemia $(\mathrm{Ca} 2+48 \mathrm{mg} /$ dL [RV: $8.5-10.1 \mathrm{mg} / \mathrm{dL}]$ ). Antibody detection tests such as ELISA for detection of anti-HIV, syphilis, and hepatitis (B and C) were negative. Chest radiographs showed lower lobe pulmonary consolidation with left pleural effusion. Abdominal ultrasonography revealed massive hepatosplenomegaly. Upper digestive endoscopy showed extensive flat ulcers secondary to mediastinal lymph node enlargement fistulized to the esophagus. Acute juvenile PCM was diagnosed by direct examination of cervical lymph node aspirate that revealed large, yeast-like cells with a thick birefringent cell wall and presenting "cryptosporulation" typical of Paracoccidioides spp. (Figure 2A). Blood cultures were negative for bacteria, but Gram staining revealed Paracoccidioides yeast-like cells (Figure 2B). Lymph node aspirate and blood cultures were grown on Sabouraud dextrose agar and mycobiotic agar at $25^{\circ} \mathrm{C}$, and the isolated pure fungus was subcultured on Fava-Netto Agar at $37^{\circ} \mathrm{C}$ for dimorphism confirmation. All cultures yielded Paracoccidioides spp. The result of serological testing for PCM using the Ouchterlony double immunodiffusion test was positive (1:256). Liposomal amphotericin $\mathrm{B}$ was prescribed (cumulative dose $9 \mathrm{~g}$ ) together with sulfamethoxazole/trimethoprim $(1,600 \mathrm{mg} / 320 \mathrm{mg}$ t.i.d.) and corticosteroids (hydrocortisone $50 \mathrm{mg}$ t.i.d.). Despite subsequent negative blood cultures and partial improvement in specific PCM clinical signs such as adenomegaly and hepatosplenomegaly, the patient's general clinical condition deteriorated and he developed multiple digital gangrene (Figure 3A and 3B) and worsening renal function. The patient died 47 days after admission (Figure 3C).

\section{Ethical considerations}

The Research Ethics Committee of INI/Fiocruz approved this study (CAAE 42590515.0.0000.5262). The patient's mother signed an institutional written consent form authorizing description of the case and the release of patient photographs.

\section{Molecular identification of fungal strains}

Genomic DNA was extracted from the yeast phase of isolates from lymph nodes and blood cultures. Molecular identification was obtained by the amplification of partial sequences of $\operatorname{arf}$ and gp43 genes $^{3,4}$. Using the Basic Local Alignment Search Tool, sequences were compared with those previously deposited in GenBank ${ }^{\circledR}$ by Matute et $\mathrm{l}^{5}$. Sequences showed $100 \%$ homology with $P$. brasiliensis $\mathrm{S} 1$. The sequences generated in this study are available from GenBank ${ }^{\circledR}$ (accession numbers MF066648, MF066649, MF066650, and MF066651).

\section{Immunological evaluation}

Lithium heparin plasma samples were stored at $-80^{\circ} \mathrm{C}$ until use. IL-1RA and IL-6 cytokines were measured using ELISA (R\&D Systems, Minneapolis, MN, USA), according to the manufacturer's instructions; results were expressed as picograms per milliliter. The detection limits for IL-6 were 3.1-300.0pg/mL and $31.2-2,000 \mathrm{pg} / \mathrm{mL}$ for IL-1RA. Peripheral blood mononuclear cells $(\mathrm{PBMC})$ were isolated by centrifugation through a Histopaque gradient (Sigma-Aldrich, St. Louis, MO, USA).

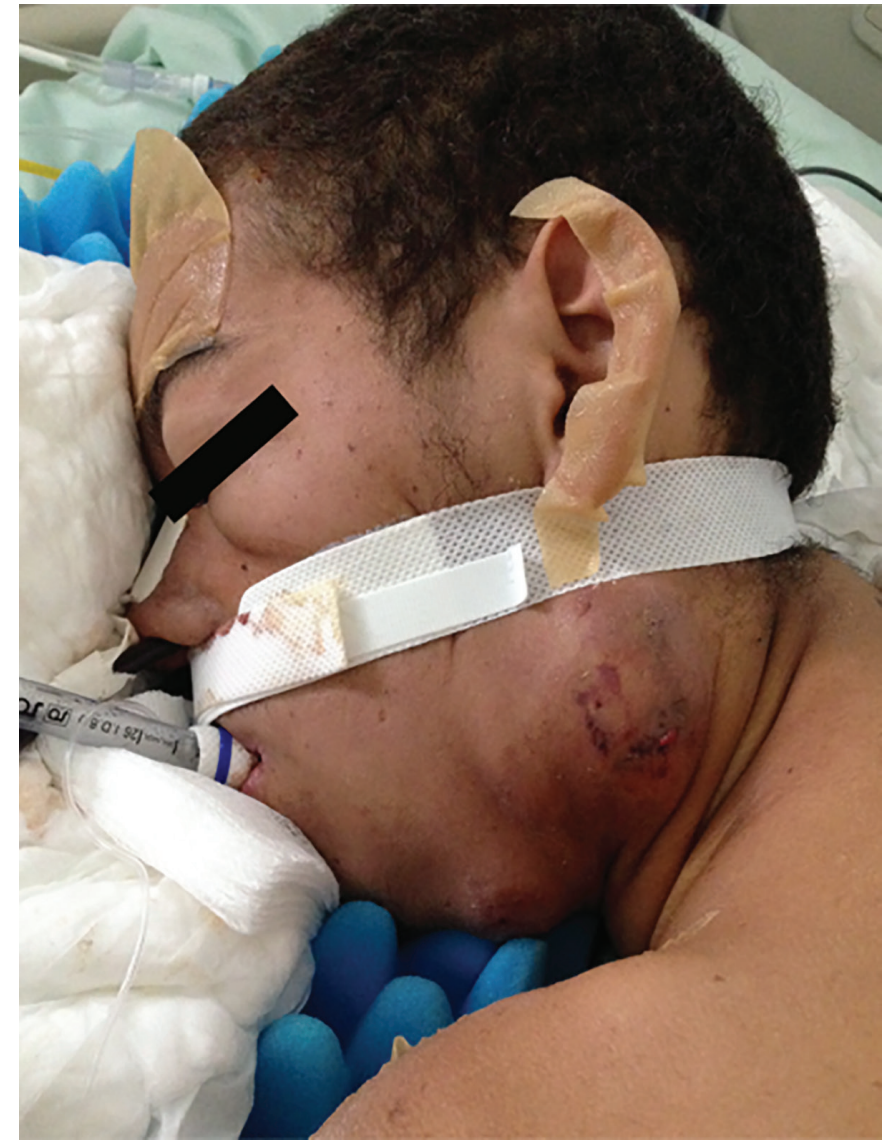

FIGURE 1: Patient at admission presenting anasarca, bulky cervical lymph nodes, and acute respiratory failure requiring tracheal intubation for oxygen supply.
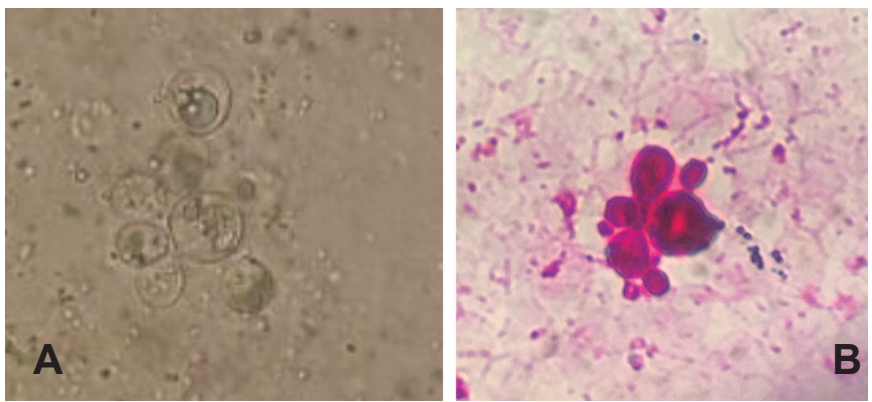

FIGURE 2: (A): Direct microscopic examination of cervical lymph node aspirate with potassium hydroxide preparation reveals large, multiple, budding yeast-like cells typical of Paracoccidioides spp. (B): Direct microscopic examination of blood culture with Gram staining reveals Paracoccidioides spp. yeast-like cells.
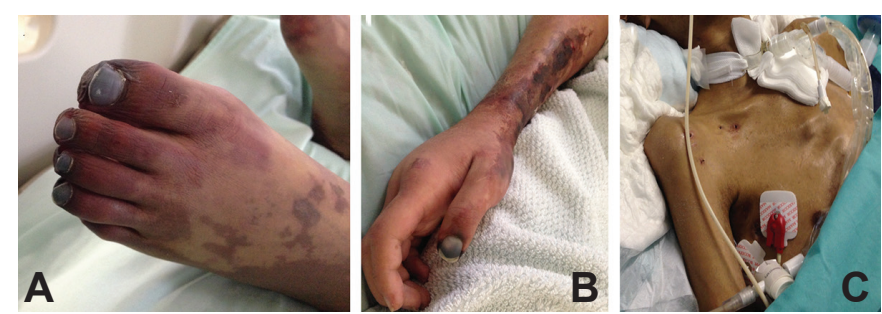

FIGURE 3: (A, B): Multiple digital gangrene as a severe complication in this patient. (C): Terminal patient with severe cachexia as a consequence of disease severity. 
Phenotypic analysis of $\mathrm{T}$ cells was conducted after incubation of $1 \times 10^{5}$ PAMC with the following specific monoclonal antibodies: anti-CD38 Pe-Cy7, anti-HLA-DR V500, anti-CD69 Pe-Cy7, anti-CD3 APC-H7, anti-CD4 PercP, and anti-CD8 APC (BD Biosciences, San Jose, CA, USA). Forty thousand events were acquired using CytoFLEX flow cytometry (Beckman Coulter Inc., Brea, CA, USA) into a lymphocyte electronic region. Subsequently, the percentage of activated $\mathrm{T}$ cells was determined using Kaluza software (Beckman Coulter Inc.). Regulatory $\mathrm{T}$ cells were characterized using a commercial kit containing anti-CD4 Pe-Cy5, anti-CD25 PE, and anti-FOXP3 FITC (BioLegend, San Diego, CA, USA). Limits for the quadrant markers were always set based on negative populations and isotype controls. Results were expressed as percentage of positive cells. The patient presented $\mathrm{CD} 38^{+} \mathrm{HLA}-\mathrm{DR}^{+}=37.5 \%$, $\mathrm{CD} 69^{+}=85.8 \%$, and $\mathrm{CD} 4^{+} \mathrm{CD} 25^{+} \mathrm{Foxp}^{+}=3.9 \%$. Moreover, a three-fold increment of inflammatory IL-6 plasma level (D1= $71.0 \mathrm{ng} / \mathrm{mL} ; \mathrm{D} 6=237.0 \mathrm{ng} / \mathrm{mL}$ ) and a decrease in anti-inflammatory IL-1RA plasma level (D1=1,456.1ng/mL; D6=918.9ng/mL) were observed after 6 days of disease progression.

\section{DISCUSSION}

PCM is a life-threatening, neglected systemic mycosis that is usually misdiagnosed, as in this case, thus protracting the correct treatment. Late diagnosis, especially of the acute juvenile clinical form, induces serious complications including death ${ }^{6}$. The mononuclear phagocytic system is the main site of infection. The lymph nodes are involved in nearly $100 \%$ of acute PCM cases, followed by the liver, spleen, and skin ${ }^{1,6}$.

Although systemic bloodstream dissemination of Paracoccidioides spp. is a typical event in PCM pathogenesis, isolation of the fungus from blood samples is unusual, being mostly reported in cases of immunosuppression ${ }^{7,8}$. The direct observation of Paracoccidioides structures in blood smears is even more rare because it indicates a high fungal burden. Both laboratory findings were observed in the present case. Together, these observations could explain a septic embolization inducing the digital gangrene observed in this patient because Paracoccidioides spp. yeast-like cells are larger than the lumen of small blood vessels in the extremities. However, the vascular and inflammatory events in septic shock are more likely to explain digital gangrene as well as organ dysfunction, such as renal failure. Septic shock can cause peripheral hypoperfusion and hypoxia, inducing gangrene of the extremities. Another even stronger hypothesis for the digital gangrene in this case is that an intense inflammatory response damaged the endothelium, causing a severe vasculitis process ${ }^{9}$.

The severity of this case can likely be ascribed to an exacerbated host response against the pathogen, as demonstrated by the immunological analysis, which presented a remarkable cell activation profile without a satisfactory $\mathrm{T}$ cell regulation response ${ }^{10,11}$. Notably, the patient showed a diminished percentage of peripheral blood $\mathrm{T}$ regulatory cells in comparison with healthy individuals $(\mathrm{CD} 4+\mathrm{CD} 25+\mathrm{Foxp} 3+=11.1 \%)$. High titers of circulating antibodies specific to the fungus (typical in acute forms of PCM) along with a high fungal burden in the bloodstream are very likely to have induced immune complex formation and complement activation. In addition, the detected decrease in anti-inflammatory IL-1RA plasma level indicates a potential for endothelial damage, which contributed to the vasculitis process. The lack of biopsy or necropsy investigation for possible vasculitis causes, including the presence of fungi, fungal antigens, or host elements, is a limitation of the present study, which was justified by the ethical considerations.

P. lutzii has been previously described in the context of worse clinical conditions, such as fatal fungemia ${ }^{2}$. To our knowledge, this is the first report of fatal septic shock, a rare clinical manifestation, caused by $P$. brasiliensis $\mathrm{S} 1$. Although there is a paucity of clinical information about this phylogenetic species, together with $P$. lutzii, P. brasiliensis also seems to be involved in other severe cases of $\mathrm{PCM}^{3,6}$. These findings indicate the need for more studies on Paracoccidioides-host interaction, with a higher number of clinical isolates obtained from patients with different clinical manifestations, treatment responses, and outcomes, to better understand the physiopathology of this neglected disease and prevent unfavorable outcomes.

\section{Acknowledgments}

The authors are grateful to Dr. Ivan Rocha Ferreira da Silva for clinical support during the patient's hospitalization and to Dr. Andrea Reis BernardesEngemann for kindly editing the figures in this manuscript. The authors would also like to thank the sequencing platform team at Oswaldo Cruz Foundation (PDTIS/FIOCRUZ) for automated nucleotide sequencing of the strains.

\section{Conflict of interest}

The authors declare that there are no conflicts of interest.

\section{Financial support}

This study was supported by the National Council for Scientific and Technological Development [304976/2013-0] to RMZ-O, and the Carlos Chagas Filho Research Support Foundation of the State of Rio de Janeiro [E26/010.002203/2015] to ACFdV.

\section{REFERENCES}

1. Shikanai-Yasuda MA, Mendes RP, Colombo AL, Queiroz-Telles F, Kono ASG, Paniago AMM, et al. Brazilian guidelines for the clinical management of paracoccidioidomycosis. Rev Soc Bras Med Trop. 2017;50(5):715-40.

2. Hahn RC, Rodrigues AM, Fontes CJF, Nery AF, Tadano T, Queiroz Jr LP, et al. Fatal fungemia due to Paracoccidioides lutzii. Am J Trop Med Hyg. 2014;91(2):394-8.

3. Marques de Macedo P, de Oliveira LC, Freitas DF, da Rocha JA, Freitas AD, Nucci M, et al. Acute paracoccidioidomycosis due to Paracoccidioides brasiliensis S1 mimicking hypereosinophilic syndrome with massive splenomegaly: diagnostic challenge. PLoS Neg1 Trop Dis. 2016;10(4):e0004487.

4. Teixeira MM, Theodoro RC, Oliveira FF, Machado GC, Hahn RC, Bagagli E, et al. Paracoccidioides lutzii sp. nov: biological and clinical implications. Med Mycol. 2014;52(1):19-28.

5. Matute DR, McEwen JG, Puccia R, Montes BA, San-Blas G, Bagagli $\mathrm{E}$, et al. Cryptic speciation and recombination in the fungus 
Paracoccidioides brasiliensis as revealed by gene genealogies. Mol Biol Evol. 2006;23(1):65-73.

6. de Macedo PM, Almeida-Paes R, Freitas DF, Varon AG, Paixão AG, Romão AR, et al. Acute juvenile paracoccidioidomycosis: a 9-year cohort study in the endemic area of Rio de Janeiro, Brazil. PLoS Negl Trop Dis. 2017;11(3):e0005500.

7. Hadad DJ, Pires MF, Petry TC, Orozco SFB, Melhem MSC, Paes RAC, et al. Paracoccidioides brasiliensis (Lutz, 1908) isolado por meio de hemocultura em um paciente portador de síndrome da imunodeficiência adquirida (SIDA). Rev Inst Med Trop Sao Paulo. 1992;34(6):565-7.

8. Caseiro MM, Etzel A, Soares MCB, Costa SOP. Septicemia caused by Paracoccidioides brasiliensis (Lutz, 1908) as the cause of death of an AIDS patient from Santos, São Paulo State, Brazil - a nonendemic area. Rev Inst Med Trop Sao Paulo. 2005;47(4):209-11.

9. Caldeira ACBF, da Cas K, Pinto TPL, Zômpero CM, Pés C, Guolo CE. Vasculite de pequenos vasos como primeira manifestação clínica de paracoccidiodomicose - relato de caso. An Bras Dermatol. 2011;86(6):1208-12.

10. Benard G. An overview of the immunopathology of human paracoccidioidomycosis. Mycopathologia. 2008;165(4-5):209-21.

11. Fortes MR, Miot HA, Kurokawa CS, Marques ME, Marques SA. Immunology of paracoccidioidomycosis. An Bras Dermatol. 2011;86(3):516-24. 